\title{
Development of Computer-Based BIPA Learning Evaluation Tools
}

\author{
Andhika Ariamaharani', Subyantoro ${ }^{2}$, U'um Qomariyah ${ }^{3}$ \\ ${ }^{123}$ Universitas Negeri Semarang, Indonesia, \\ 1andhika.ariamaharani@gmail.com, bintoro@mail.unnes.ac.id, \\ uum@mail.unnes.ac.id
}

\begin{abstract}
Current technological development are directly proporsional to development of learning Indonesian as a foreign language both in Indonesian and abrod. The purpose of this research was to find (1) the computer-based BIPA learning evaluation requirements, (2) the fundamental of developing computer-based BIPA learning evaluations, (3) computer-based BIPA learning evaluation prototype, and (4) validator assessment results and improvement suggestions. The design of this research was research and development. The data was obtained from questionnaires of requirement, interview, and observation. Descriptive qualitative analysis was used in this research. The results of the research include characteristics of computer-based BIPA learning evaluation tools and fundamental in developing computer-based BIPA learning evaluation tools. The results of the assessment provided by the expert amounted to 81,25 while the BIPA teacher scored 77,50. Suggestions for improvement include background display and development of speaking skills and language competencies. The limitations of this product are not yet able to present applications than can record sound.
\end{abstract}

Keywords: Foreign, Learning Evaluation Tools, Computer-based, BIPA level Al

\section{PENDAHULUAN}

Dewasa ini perkembangan bahasa Indonesia sebagai bahasa asing berkembang sangat pesat. Saat ini tidak hanya pemerintah Indonesia saja yang sadar akan perkembangan bahasa Indonesia dengan mendirikan kelas bahasa Indonesia untuk penutur asing, tetapi beberapa negara lain telah sadar akan perkembangan bahasa Indonesia dengan mengirimkan mahasiswanya ke Indonesia atau mengundang pengajar dari Indonesia ke negaranya [1]. Pembelajaran BIPA disesuaikan dengan tujuan dan karakteristik penutur asing. Tujuan mereka antara lain, mampu berkomunikasi untuk kepentingan sehari-hari, untuk kepentingan akademik seperti perkuliahan atau pekerjaan, dan kepentingan pekerjaan [2]. Karakteristik pemelajar BIPA antara lain baru mengenal bahasa Indonesia, belum memiliki kemampuan komunikatif, memiliki semangat belajar yang tinggi, dan tepat waktu.

Materi BIPA berdasarkan standardisasi PPSDK dalam buku ajarnya "Sahabatku Indonesia: Tingkat A1" [3] terdiri atas kompetensi keterampilan berbahasa dan kompetensi bahasa. Kompetensi bahasa terdiri atas materi tata bahasa dan kosakata. Strategi yang dapat digunakan dalam pengenalan kosakata antara lain dengan menggunakan gambar, foto, objek langsung, 
atau dengan memilih kosakata secara acak pada buku teks untuk mengetahui pelafalan penutur asing [4]-[6].

Penutur asing juga mempelajari jenis teks, salah satunya adalah teks deskrpsi. Teks deskripsi berisi informasi pengambaran objek secara rinci oleh penulis secara subjektif dengan kata-kata dalam penyampainnya agar pembaca dapat melihat dan merasakan penggambaran yang disampaikan [7]. Ciri-ciri teks deskripsi adalah objek digambarkan dengan jelas dan terperinci; mampu membuat pembaca merasakan apa yang ditulis oleh pengarang; menggunakan kata-kata konkret dan majas untuk memperindah tulisan [8]. Struktur teks deskripsi terdiri atas identifikasi, deskripsi bagian, dan penutup [9].

Saat ini perkembangan teknologi banyak dimanfaatkan dalam pembelajaran bahasa asing, salah satunya adalah pembelajaran BIPA. Pengembangan yang dilakukan ada yang berupa aplikasi atau seperangkat alat tes yang digunakan sebagai media pembelajaran ataupun alat evaluasi pembelajaran. Salah satu penelitian yang berkaitan dengan pengembangan alat tes adalah milik Alawiyah [10]. Selain itu pengembangan pembelajaran bahasa dengan komputer juga telah dilakukan oleh Yang [11]. Namun, saat ini masih jarang ditemukan pengembangan alat evaluasi pembelajaran BIPA dengan memanfaatkan teknologi dan mengembangkan satu tema. Berkaitan dengan hal tersebut tujuan dari penelitian ini meliputi 1) menganalisis kebutuhan pembelajaran BIPA terhadap alat evaluasi pembelajaran aspek memberi dan meminta tentang ciri orang, binatang, dan benda berbasis komputer, 2) merumuskan prinsipprinsip evaluasi dalam pembelajaran BIPA aspek memberi dan meminta tentang ciri orang, binatang, dan benda 3) menghubungkan prototipe alat evaluasi pembelajaran berbasis komputer sesuai kebutuhan pengajar dan pemelajar BIPA, 4) mendeskripsi penilaian ahli terhadap alat evaluasi pembelajaran pemelajaran berbasis komputer.

Tujuan pembelajar BIPA berkaitan erat dengan kebutuhan penutur asing dalam mempelajari bahasa Indonesia yang bersifat akademis maupun praktis, serta memberdayakan pengajar serta pembelajaran BIPA ke dalam pengajaran yang berkembang secara professional [12].

Evaluasi pembelajaran merupakan poin penting dalam pembelajaran yang tak terlepas dari tujuan pembelajaran dan proses pembelajaran [13]. Tujuan evaluasi adalah untuk mengetahui kemampuan pemelajar dan keberhasilan pengajar dalam proses pembelajaran serta meningkatkan kualitas pengajaran [14]. Prinsip evaluasi pembelajaran dilakukan secara terusmenerus dan saling berhubungan untuk mengetahui perkembangan pemelajar dalam proses pembelajaran [15].

\section{METODE PENELITIAN}

Penelitian ini menggunakan metode Research and Development. Pengumpulan data menggunakan metode wawancara, angket, dan observasi [16]. Sumber data dalam penelitian ini adalah (1) buku "Sahabatku Indonesia: tingkat A1, (2) hasil angket kebutuhan pengajar dan pemelajar BIPA, (3) hasil penilaian pengajar BIPA, dan (4) saran pengajar BIPA. Analisis data dalam penelitian ini menggunakan statistik deskriptif. Rancangan alat evaluasi pembelajaran BIPA berbasis komputer adalah permainan edukasi berbasis komputer dengan memfokuskan pada satu tema yang terdapat pada silabus pembelajaran BIPA tingkat A1 dalam bahan ajar "Sahabatku Indonesia". 


\section{HASIL DAN PEMBAHASAN}

Analisis kecendrungan kebutuhan yang dilakukan terhadap pemelajar dan pengajar BIPA didapatkan bahwa 1) materi yang ditampilkan merupakan jenis binatang dan benda yang berada di lingkungan sekitar atau umun dengan disisipkan muatan budaya Indonesia, 2) bentuk alat evaluasi yang dipilih adalah pilihan ganda, menjodohkan, dan isian dengan jumlah soal 5-10 butir, 3) komponen yang perlu ditambahkan ke dalam program adalah kamus mini, contoh soal, dan cara pengerjaan, 4) latar belakang tampilan dan musik dalam program menampilkan keanekaragaman Indonesia dan jenis ilustrasi yang digunakan adalah foto.

Materi yang ditampilkan juga sesuai dengat SK dan KD serta bahasa yang dikeluarkan PPSDK dalam buku ajar "Sahabatku Indonesia Tingkat A1". Muatan budaya yang disisipkan dalam program adalah muatan budaya Indonesia dalam aspek kesenian, rumah adat, maupun permainan tradisonal. Muatan budaya juda disisipkan ke dalam latar belakang tampilan dan musik yang ada di dalam program. Bahasa pengantar yang digunakan di dalam program adalah bahasa Indonesia.

Prinsip dalam aspek materi adalah prinsip keautentikan, sehingga materi yang disampaikan sesuai dengan kenyataan di lapangan. Prinsip dalam aspek alat evaluasi pembelajaran adalah prinsip kepraktisan. Prinsip tersebut mengarahkan alat evaluasi pembelajaran untuk tidak membutuhkan biaya mahal, tidak membutuhkan waktu lama dalam penyelesaian, mudah dilaksanakan, dan tidak membutuhkan penskoran yang lama. Prinsip dalam aspek pengembangan alat evaluasi pembelajaran berbasis komputer adalah prinsip inovasi, dimana terdapat gagasan baru dalam mengembangkan suatu alat evaluasi pembelajaran. Prinsip relevansi menjadi dasar dalam aspek tampilan. Ilustrasi serta latar belakang tampilan dan musik yang dihadirkan di dalam program disesuaikan dengan materi dan muatan budaya yang dibutuhkan oleh pemelajar BIPA.

Prototipe alat evaluasi pembelajaran BIPA berbasis komputer disajikan sebagai berikut a) halamana awal, b) menu inti, c) menu keterampilan berbahasa, d) menu kompetensi bahasa, e) menu evaluasi akhir, f) menu kamus mini, g) menu informasi, h) menu pengaturan, dan i) menu keluar.

Hasil penilaian yang diberikan oleh ahli sebesar 81,25 sedangkan oleh pengajar BIPA mendapat nilai 77,5. Perbaikan dilakukan berdasarkan pada penilian dan saran validator agar alat evaluasi pembelajaran BIPA berbasis komputer semakin sempurna. Saran tersebut meliputi 1) perbaikan pada latar belakang tampilan program, 2) soal yang ditampilkan dalam keterampilan berbicara dan kompetensi bahasa, 3) evaluasi akhir disesuaikan dengan kompetensi keterampilan berbahasa dan penambahan tombol kembali ke menu inti, 4) penambahan unsur permainan tradisional pada menu kamus mini, dan 5) ketentuan tombol kembali pada keterampilan menyimak.

Peneliti melakukan analisis meliputi 1) perbandingan karakteristik dengan hasil uji validasi, 2) keberterimaan program, 3) jangkauan program, 4) keunggulan program, dan 5) keterbatasan program. Analisis tersebut dilakukan berdasarkan hasil penilaian yang telah dilakukan oleh pengajar BIPA dan ahli.

Karakteristik yang diperoleh melalui analisis kebutuhan pengajar dan pemelajar kemudian dibandingkan dengan program yang telah dinilai oleh pengajar dan ahli. Beberapa hal belum sesuai dengan karakteristik yang diinginkan seperti penggunaan foto sebagai latar belakang program tidak bisa dilakukan karena adanya perbedaan resolusi. Kemudian muatan budaya yang ditampilkan hanya sebatas pada latar belakang tampilan dan musik saja. Beberapa perubahan juga dilakukan sesuai dengan saran yang diberikan oleh penilai, diantaranya penambahan waktu pengerjaan dan bentuk soal. Penelitian ini sangat berbeda dengan 
penelitian yang dilakukan oleh Alawiyah [10]. Perbedaan tersebut terletak pada tema dan keterampilan yang dijadikan subjek penelitian.

Keberterimaan program dilakukan dengan menyesuaikan isi program dengan kebutuhan pengajar dan pemelajar serta teori yang mendukung. Salah satu isi program yang disesuaikan dengan kebutuhan pengajar dan pemelajar adalah keberadaan kamus mini yang dilengkapi dengan ilustrasi. Keberadaan ilustrasi membantu pemelajar dalam memahami suatu benda dengan namanya. Hal ini sesuai dengan pendapat Alqahtani [6] mengenai teknik yang dapat digunakan oleh pengajar untuk pembelajaran kosakata adalah dengan ilustrasi dan gambar. Materi yang disusun di dalam program telah disesuaikan dengan kebutuhan pemelajar dalam mengenal lingkungan Indonesia. Sesuai dengan prinsip pembelajaran BIPA yang dikemukakan oleh Kusmiatun [1], yaitu 1) relevan, 2) aktual, faktual, dan kontekstual, dan 3) fleksibel.

Keberadaan alat evaluasi pembelajaran BIPA berbasis komputer dengan menampilkan empat keterampilan bahasa masih jarang ditemukan. Oleh sebab itu, jangkauan program alat evaluasi pembelajaran BIPA aspek deskripsi tentang ciri-ciri orang, binatang, dan benda bagi pemelajar BIPA memiliki harapan pemasaran yang tinggi dan dapat dikembangkan secara global. Adapun strategi yang dapat dilakukan, yaitu 1) mengajak instansi terkait seperti Balai Bahasa, APPBIPA, dan universitas penyelenggara BIPA mengembangkan program alat evaluasi pembelajaran, 2) mengujicoba program, 3) mensosialisasikan program, dan 4) mempromosikan program.

Keunggulan dari program hasil penelitian ini adalah memudahkan pemelajar BIPA dalam berlatih mengenal ciri-ciri orang, binatang, dan benda. Selain melatih pemelajar dengan latihan soal, pemelajar juga dapat memperkaya kosakata dengan adanya kamus mini di dalam program. Pemelajar dapat berlatih secara mandiri atau didampingi oleh pengajar BIPA. Soal yang dikembangkan di dalam program sudah menunjang ketercapaian kompetensi dasar keterampilan berbahasa dan bahasa pemelajar BIPA secara mikro. Hal tersebut sesuai dengan pendapat Mardapi mengenai tujuan evaluasi pembelajaran mikro, yaitu bertujuan untuk mengetahui capaian belajar pemelajar [17][18].

Keterbatasan waktu dan biaya yang menyebabkan tahapan penelitian hanya sampai tahap penilaian ahli atau uji validasi prototipe dan perbaikan produk. Keterbatas lain yang peneliti alami adalah program ini hanya mengembangkan satu tema pembelajaran BIPA bagi pemelajar BIPA tingkat A1. Selain itu, program yang dikembangkan oleh peneliti belum mampu menghadirkan aplikasi yang dapat merekam suara.

\section{SIMPULAN}

Simpulan penelitian ini antara lain adanya karakteristik yang diperhatikan berdasarkan analisis kecendrungan kebutuhan, yaitu 1) aspek pembelajaran BIPA/materi, 2) aspek alat evaluasi pembelajaran, 3) aspek pengembangan alat evaluasi pembelajaran berbasis komputer, dan 4) aspek tampilan. Prinsip pengembangan alat evaluasi pembelajaran BIPA berbasis komputer aspek deskripsi tentang ciri-ciri orang, binatang, dan benda meliputi 1) prinsip keautentikan, 2) prinsip kepraktisan, 3) prinsip inovasi, dan 4) prinsip relevansi. Analisis kebutuhan menghasilkan prototipe alat evaluasi pembelajaran BIPA berbasis komputer yang meliputi a) halamana awal, b) menu inti, c) menu keterampilan berbahasa, d) menu kompetensi bahasa, e) menu evaluasi akhir, f) menu kamus mini, g) menu informasi, h) menu pengaturan, dan i) menu keluar. Hasil penilaian yang diberikan oleh ahli sebesar 81,25 sedangkan oleh pengajar BIPA mendapat nilai 77,5. Nilai tersebut berasal dari rata-rata jumlah rata-rata nilai setiap aspek penilaian. Saran perbaikan yang diberikan validator 
meliputi tampilan latar belakang dan pengembangan soal maupun teknis pada keterampilan berbahasa, kompetensi bahasa, dan evaluasi akhir.

\section{REFERENCES}

[1] A. Kusmiatun, "Mengenal BIPA (Bahasa Indonesia bagi Penutur Asing) dan Pembelajarannya," Yogyakarta: K-Media, 2016.

[2] L. Nurlina and E. S. Israhayu, "BIPA Learning Material Development for Empowering Thailand Students' Writing Competence," Educare, vol. 7, no. 1, 2014.

[3] N. Novianti and I. Nurlaelawati, "Sahabatku Indonesia Tingkat A1." Badan Pengembangan dan Pembinaan Bahasa: Pusat Pengembangan Strategi dan ..., 2016.

[4] A. Khamkhien, "Thai Learners' English Pronunciation Competence: Lesson Learned from Word Stress Assignment.," J. Lang. Teach. Res., vol. 1, no. 6, 2010.

[5] N. K. Ariustini, I. N. Martha, and I. N. S. Sudiara, "Pemanfaatan Objek Langsung Untuk Meningkatkan Keterampilan Menulis Paragraf Deskripsi Siswa Kelas Xd Sma Negeri 1 Kintamani," J. Pendidik. Bhs. dan Sastra Indones. Undiksha, vol. 2, no. 1, 2014.

[6] M. Alqahtani, "The Importance of Vocabulary in Language Learning and How to be Taught," Int. J. Teach. Educ., vol. 3, no. 3, pp. 21-34, 2015.

[7] U. N. Qalbi, R. Mantasiah, J. Jufri, and Y. Yusri, "Efektivitas Model Pembelajaran Kooperatif Tipe Teams Games Tournaments dalam Keterampilan Menulis Bahasa Jerman Siswa Kelas XII IPA SMA Negeri 1 Bontonompo Kabupaten Gowa,” Indones. J. Educ. Stud., vol. 20, no. 1, 2017.

[8] E. Nasrillah, E. Kosasih, and K. Kurniawan, "Teks Eksplanasi Sebagai Bahan Ajar Bahasa Indonesia Di Kelas Xi Sman 5 Bandung (Kajian Deskiptif Kualitatif terhadap Fungsi, Struktur dan Kaidah Kebahasaan dalam Proses Pembelajaran Berbasis Genre)," Diglosia J. Pendidikan, Kebahasaan, dan Kesusastraan Indones., vol. 3, no. 1, 2019.

[9] M. P. Pardiyono, "Pasti Bisa! Teaching Genre-Based Writing," Yogyakarta Penerbit ANDI, 2007.

[10] W. S. Alawiyah, "Pengembangan Tes Keterampilan Menulis Sebagai Upaya Penyiapan Alat Uji Kemahiran Berbahasa Indonesia Bagi Penutur Asing," Bahtera Bhs. Antol. Pendidik. Bhs. dan Sastra Indones., vol. 1, no. 6, 2013.

[11] Y. Yang, "Computer-assisted Foreign Language Teaching: Theory and Practice.," J. Lang. Teach. Res., vol. 1, no. 6, 2010.

[12] A. E. Prasetiyo, "Pengembangan Bahan Ajar BIPA Bermuatan Budaya Jawa bagi Penutur Asing Tingkat Pemula." Universitas Negeri Semarang, 2015.

[13] A. Suharsimi, "Dasar-Dasar Evaluasi Pendidikan," Jakarta Bumi Aksara, 2009.

[14] H. M. Sukardi, "Evaluasi Pendidikan Prinsip dan Operasionalnya," Jakarta Bumi Aksara, 2008.

[15] Y. A. Putra, "Pelaksanaan Evaluasi Pembelajaran Pendidikan Agama Islam Di Sekolah Menengah Atas Negeri 1 Kuantan Mudik Kabupaten Kuantan Singingi." Universitas Islam Negeri Sultan Syarif Kasim Riau, 2014.

[16] M. Rahardjo, "Metode Pengumpulan Data Penelitian Kualitatif," 2011.

[17] M. Djemari, "Teknik Penyusunan Instrumen Tes dan Non Tes," Yogyakarta: Mitra Cendekia, 2008.

[18] K. Saddhono, Suhartatik, Bagiya, Widodo, and H. Wahyono, "Learning vocabularies using multimedia-based Teaching Indonesian to Speakers of Other Languages 
(TISOL)," in Journal of Physics: Conference Series, 2019, p. 012108. 